\title{
La Ley de Montes de 8 de junio de 1957 y el Registro de la Propiedad
}

\section{Antecedentes legislativos y jurisprudenciales}

Viene ya del siglo pasado la lucha que la Administración forestal emprendió contra las constantes usurpaciones de que era objeto el patritinonio forestal español, en detrimento de la riqueza nacional.

La $R$. $O$. Se 4 die abrii de 1883 , saltando por encima del viejo individualismo liberal, inicia la defensa del patrimonio forestal, frente a quienes se amparaban en el Registro de la Propiedad por medio de la información posesoria, sin citación ni audiencia de las Corporaciones interesadas. Su artículo $1^{\circ}$ establece que los Gobernadores umantengan al Estado, los pueblos - los establecimientos públicos, en la posesión de todos aquellos terrenos montuosos comprendidos en las re'aciones... o en el $\mathrm{Ca}$ tálogo..., $\mathrm{y}$ en que se hayan ejercido actos posesorios por sus respectivos dueños o por la Administración.. Contra esta presunción no se admite otra prueba que las informaciones posesorias inscritas que acrediten la posesión durante treinta años «a ciencia y paciencia de los dueños de los predios" (art. 2). Lo mismo la R. O. de 14 de enero de 1893.

Esta orientación es consagrada de manera tajante por eí R. D. de 1 de febrero de 1901 , que en pugna con presepros fun damentaies de nuestro ordenamiento juridico, otorga a ia in. 
clusión de un monte en el Catálogo de utilidad pública la presunción de posesión, que prevalece sobre las presunciones iegitimadoras del Registro de la Propiedad, sin perjuicio del mejor derecho al dominio que habría de ventilarse ante los tribunales ordinarios (Sent. 8 marzo 1912).

Dicha presunción es perfilada después por la Jurisprudencia; como una presunción iuris tanium.

Posteriormente, la reforma hipotecaria de 1927, hace prevalecer el Registro sobre la base de la presunción posesoria del derecho inscrito.

La R. O. de 20 de febrero de 1930, vuelve, sin embargo, al criterio proteccionista de la $R$. Q. de 1883 , y proclama que la prescripción de los montes públicos por los particulares, frente a la Administración, es la extraordinaria de treinta años.

El viejo problema de los montes públicos en relación con el Registro de la Propiedad, vuelve a replantearse -esta vez con rango de ley-, en la actual de 8 de junio de 1957, cuyas soluciones vamos a examinar en concordancia con el Registro de la Propiedad.

\section{LA NUEva LEY DE Montes}

Su Exposición de motivos pone de manifiesto la necesidad de una firme defensa de la propiedad forestal pública, frente a los "fuertes ataques y segregaciones que realizaron avisados y logreros, manejándose hábilmente èn la complejidad y entresijo de disposiciones, preceptos y procedimientos...) Para lo cual adopta la nueva Ley dos medidas fundamentales:

1) Catálogo de montes de utilidad pública, cuyo valor jurídico refuerza, según veremos.

2) Obligación de inscribir en el Registro de la Propiedad de los montes de utilidad pública, tanto los deslindados, como los que no hubiesen sido objeto de esta operación (articulo 11-1 y 3).

Esta obligación de inscribir, estatuída con carácter generail por el artículo 24 del Reglamento hipotecario, se previno también por la: Ley de Régimen local (art. 199) y Reglamento 
de bienes de las Enidades locales (arit. 35). Málas ahora se impone con lina paríicularidad: la çe referirse aí objeto exclusivo de la propieciad forestal pública.

Esto nos lieva a examinar, someramenite, la naturaleza de la inscripción ordenada por el artículo $\mathbf{1 1 .}$

1. Naruralezci cie la inscripción.

La Ley Hipotecaria española consagró, entre los sisiemas posibles, el de la inscripción declarativa y facultativa, en concordancia con la teoría del título y el modo recogida por nuestro Cócigo civil (arts. 609 y 1095), si bien se trató de estimular la inscripción con la fórmula ircorrecta del artículo 313 de la Ley Hipotecaria, como ha puesto de relieve Angel Sanz (1). Sólọ en materia de hipotecas la inscripción tiene carácter constitutivo.

Frente a este sistema registral, la nueva Ley de Montes impone la inscripción obligatoria de ésios, y ce un mocio más terminante todavía que el propio Regiamento de bienes de las Entidades iocales (referente a bienes inmueb'es y cierechos reales); al imponer en caso de incumplimiento, la subsanación de la falta por solicitud del Registrador ante la Dirección General de Montes, quien exigirá responsabilidades al funcicnario negligente (art. 11, ap. 3, párr. 3).

2. Fundamento del nuevo sistema.

Se impone la inscripción obligatoria, porque para esta clase de propiedad constituye una "medida precautoria" o de defensa - como seña'a la Exposición de motivos- frente a usurpadores "avisados". Es, como veremos, una manera de evitar el fraude legal y ei abuso del derecho.

No cabe duda que el Registro proporciona garantías. Pero

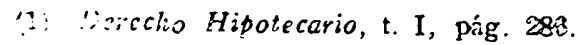


no es menus cierio que tocio sistema de garantías registrales puede ser utilizado por ei no propietario, cuancio ia entrada en el mismo se fuerza de marera encubierta, o se deja abierio algún portillo sin posible "coniroi” por parte del Registrador.

La legislación y la fe pública registral, con sus drásticas consecuencias, han llevado sin ducia al legislador, a imponer, en prevención, la necesidad de inscribir los montes públicos, para evitar el perjuicio derivado de la aparición de un tercero amparado por el Registro; ya que éste sería protegido por el artículo 34 de la Ley Hipotecaria, que es -como dice Núñ̃ez Lagos- un modo de retener o mantener como consecuencia de la irreivindicabilidad del derecho inscrito (2), o un modo de extinguir la propiedad, la del Código civil, en aras de la seguridad del tráfico jurídico: el artículo 34 de la Ley Hipotecaria, como condición resolutoria implícita en todo título sujeto $a$ inscripción $y$ no inscrito (3).

De esta forma, el subadquirente de un usurpador de terrenos de montes que ha entrado en el Registro, está protegido por la fe pública registral, si reúne los requisitos del artículo 34 de la Ley Hipotecaria.

La clave de la cuestión está, por tanto, en descubrir el falso portillo utilizádo por el usurpador de parcelas, roturadas arbitrariamente en montes públicos, para entrar en el Registro de la Propiedad. Y la experiencia profesional nos señala de modo inmediato, con visos de preocupación y advertencia, al artículo 205 de la Ley Hipotecaria. Pasados los dos años de suspensión de la fe pública registral (art. 206), ésta entrará en juego a través del artículo 34. Entonces, el fraude se habrá consumado.

$\mathrm{La}_{\mathrm{a}}$ inscripción de los montes era, por tanto, de una necesidad insoslayable, si se quería evitar que este "entresijo" de preceptos en la actualidad, fuera manejado por los "avisados" usurpadores.

(2) Perfiles de fe pública, en Anuario de Derecho Civil», 1949, t. VI, pág. 28.

(3) Realidad y Registro, en Revista General de Legislación y Jurisprudencià, 1945, pág. 430. 
Hoy día, sin embargo, la fuerte presunción posesoria y el carácter de registro público que emana del Catálogo de montes, junto a la paralización del artículo 41 de la Ley Hipotecaria, que establece la Ley de Montes, refuerzan cons derablemente la defensa juridico-patrimonial de los montes púb.icos.

\section{Inmatriculación de parcelas colindantes con los montes pi- blicos.}

La posibilidad de inscribir fincas en el Registro español sin una comprobación oficial de su existencia y de sus caracteres físicos; la imperfecta descripción o identif:cación de los montes, especialmente los no deslindados; y la facilidad de los particulares colindantes con montes públicos, para lega'izar sus posibles roturaciones, al amparo del articulo 205 de la Ley Hipotecaria, hacia menguar notablemente la garantía de la previa inscripción, en este último supuesto.

Al no figurar el trozo roturado en el Indice del registro de fincas inscritas, por tratarse de una porción material de otra mayor, con linderos y extensión diferentes del monte de propios, era casi segura la entrada en el Registro de la finca o parcela roturada, sin más aviso oficial que el escrúpu'o y celo secretarial de observar detenidamente el edicto remitido al Ayuntamiento por el Registro de la Propiedad, para poder inducir de los linderos de la finca que se pretende inscribir, la posibilidad de que se trate de una usurpación del patrimonio forestal de! Municipio.

Ello representa la quiebra del sistema de seguridad juridica y principio de especialidad -identificación de fincas- del sistema hipotecario español (4).

De ani que recibamos con elogio la garantía que establece

(4) V. Ventura-Travesset: La identificación de finces, en eRevista Critica de Derecho Inmobiliario alos reconocimientos catastrales y el Registro de la propiedad rústicas, Roma, abr' de 19ã3, de Sir Bernard O. Binns 
1a nueva Ley de Montes, al determinar en el apartado 4) de su articulo 11 que "cuando se trate de inmatricular en el Registro de ia Propiedad fincas colindantes con los montes catalogados, en la descripción de dichas fincas deberá expresarse claramente esta circunstancia y se suspenderá la inscripción solicitada, si no se acompaña al título certificación de la Administración forestal que acredite que las fincas que se pretenden inscribir no están incluilas en los montes catalcgados".

La finalidad del precepto, como decimos, es de elogiar. Sin embargo, creemos que en un plano estrictamente jurídico, la comprobación oficial de las fincas a inmatricular en el Registro españo: -deficiencia que hay que subsanar-es algo que debe corresponder al Catastro.

La importancia del Catastro se puso de relieve por la Ley Hipotecaria de 1909 , y de un modo preciso en el preámbulo de la Ley de Catastro de 1924: "el Catastro dará al Registro, substancia física, material, corporal; el Registro al Catastro, substancia juridica, derechos de pertenencia en las parcelas".

E! Catastro -escribe Roca Sastre- haciendo especial referencia al artículo 205, puede ofrecer al Registro un medio perfecto de inmatriculación de fincas (5). Esta es la base que de lege ferenda propugnamos para el sistema inmobiliario español, y: la que la Ley de Montes debiera de haber llevado a su texto positivo en aquellas zonas que están catastradas, dejando el Catálogo con deslinde, de modo provisional, para las restantes.

Jurídicamente, la técnica del Catálogo -inventario a grosso modo- no es perfecta, "ya que hacer artícu'o de fe-escribe Martín Retortillo- la inscripción en el Catálogo de Montes es una verdadera anomalía, pues son muchos los expedientes de inclusión de un monte que, por el sistema de publicidad que al mismo se le da, pasan totalmente desapercibidos para los particulares directamente afectados" (6).

(5) Derecho Hipotecario, t. III, pág. 750 .

(6) La posesión de los montes públicos, en aRevista General de Legislación Y Jurisprudencias, 1945. 
El deslinde ofrece ya una garantía a efectos de certificación. Pero es una segunda "fase», distinta de la inclusión en el Catálogo, y configurada más bien como un modo de sanear la propiedad.

El Catálogo en sí y por sí, no aporta al Registro de la Propiedad sustancia física, material, como sería la determinación topográfica de enclavados y fincas colindantes con el monté.

\section{El deslinde en relación con el Catálogo.}

Una vez incluidos los montes en el Catálogo - con el beneficio jurídico de las presunciones correspondientes- debe procederse, como advierte el preámbulo de la Ley, al "saneamiento legal del sector forestal público", mediante la realización de los deslindes y amojonamientos.

Para la finalidad del Catálogo, es indispensable el deslinde del monte, que permitirá recuperar todas aquellas parcelas enclavadas o colindantes, que hayan podido ser roturadas, siempre que no hayan llegado a prescribir o estén protegidas por la fe pública registral. A este respecto y en relación con el $\mathrm{Re}$ gistro de la Propiedad, distingue el artículo 11 tres supuestos:

1) Monte incluído en el Catálogo y que haya sido deslindado: Será título para la inscripción, la certificación de dominio, acompañada, si existe, del plano topográfico.

2) Monte incluído en el Catálogo y en estado de deslinde: a) Se extenderá anotación preventiva de deslinde sobre las fincas relacionadas con el monte objeto del mismo. b) Si en plazo de cuatros años (duración de la anotación preventiva) la Administración forestal demandara al titular de las fincas afectadas por aquella, la anotación de demanda surtirá efecto respecto de tercero, desde la fecha de anotación del deslinde. (Extremo intimamente relacionado con lo dispuesto por el artículo 69 de la Ley Hipotecaria).

La resolución definitiva del expediente es título suficiente, según el caso, para la inmatriculación del monte, rectificación de la descripción de las fincas afectadas y cancelación de las anotaciones. 
3) Monte incluído er ei Catálogo, pendiente de deslinde: Se inscribirá mediante certificación de la Administración forestal. En caso de notoria discordancia con la realidad, la Administración forestal practicará reconocimiento del terreno, estableciendo provisionalmente la cabida y linderos del mismo.

De este apartado podemos inferir que el Catálogo de por si no ofrece las suficientes garantías para la comprobación oficial de enclavados y parcelas colindantes con el monte inventariado, precisando del deslinde o reconocimiento oficial del terreno para certificar si una parcela está o no dentro del monte catalogado.

\section{El Catálogo de Montes y el Registro de la Propiedad.}

La nueva Ley otorga al Catálogo de Montes de utilidad pública, la categoría de Registro púbiico de carácter administrativo (art. 6). Le concede estos importantes efectos jurídicos: 1) Presunción de pertenencia o titularidad de! monte inventariado. Esta titularidad sólo podrá ser impugnada en el juicio declarativo ordinario de propiedad ante los Tribunales civiles. 2) Presunción de posesión en 1a que serán mantenidos el Patrimonio Forestal del Estado o Entidad pública y asistidos para la recuperación de sus montes por los Gobernadores civiles en todo caso, sin que esta posesión pueda ser combatida ante los Tribunales de Justicia por medio de interdictos o procedimientos especiales (art. 10); quedando, además, $s i n$ electo, el ejercicio de acciones reales procedentes de derechos inscritos - artículo 41 de la Ley Hipotecaria- (art. 11-6).

Vuelve la nueva Ley al criterio proteccionista de la $R$. $O$. de 1883 (art. 2), resolviendo la pugna existente con el artículo 41 de la Ley Hipotecaria, conforme a la R. O. de 1930 a favor del Catálogo de Montes, mientras no se deciare la propiedad por el juicio declarativo ordinario.

Se produce pues, una excepción en favor de esta propiedad. Su carácter público, el interés social y económico que para la nación representa esta propiedad especial, justifica por la parti- 
cularidad de sus fines, un estatuto juridico distinto en su forma de ser y en su forma de apropiación. No se trata de un privilegio administrativo, como única base de fundamentación de tan importantes efectos, sino de una diversificación de propiedades, pública y privada.

"Consideramos los montes -dice Alvarez Gendín- como un dominio público especial que está afecto a un interés públi.$c o$, si bien con excepciones a las líneas y características generales del dominio público". "No debe haber duda del carácter público de los montes catalogados»(7).

Gascón y Marín incluye a los montes de utilidad pública, como de "dominio público", comprendido en el número 2 del artículo 339 del Código civil -idestinados al fomento de la riqueza nacional- (8).

García Oviedo entiende que no es exhaustiva la enumera-. ción de bienes de dominio público municipal aparecida en la Base 19 de la Ley de 17 de julio de 1945 de Régimen local, y que deben ser públicos por analogía, como los montes provinciales catalogados que lo son por la Base 47 (9).

La clásica buena fe del tráfico jurídico, en la que la propiedad privada se desenvuelve por su dinamismo, no puede servir. de vehículo para la apropiación del dominio público. forma estática de existencia y desenvolvimiento de instituciones orgánicas que constituyen las bases fundamentales y políticas de la nación.

Acudir al Registro de la Propiedad por el portillo del artículo 205, es tomar el Registro, como dice González Palomino, como un "burladero" (10): es un fraude a la ley. $Y$ después de defraudar a la Administración y a la ley, hacer valer su "derechon por el procedimiento del artículo 41, es ya un abuso de derecho que va contra el Derecho, no privado, sino público de

(7) El Dominio público, 1956, págs. 158 y 166.

(8) Tratado de Derecho Administrativo, t. I, 195̄1, págs. 398-399.

(9) Cit. por Alvarez Gendfo en obra indicada, pág. 1 C0.

(10) Cit. por NúÑez Lagos, en Revista General de Regislación y Juiisprudencian: Tercero y fraude eir el Registro de la Propiedad, mayo, 19j0, páginas 507,603 y 607 . 
la nación, que está por encima de todo interés egoísta y sin escrúpuio.

De ahí, que el dominio público, por este hecho, lleve implícito en sí la apariencia de su titularidad y que la prescripción del mismo sólo pueda reaizarse por el plazo máximo reconocido en Derecho de treinta años. La Ley de Montes, en evitación del posible fraude registral, paraliza en todo caso el procedimiento del artículo 431 de la Ley Hipotecaria. Si bien es de notar que en el caso de hallarse previamente inscrito el monte, disposición obligada de la nueva Ley, tampoco tendría lugar dicho procedimiento en virtud de lo establecido por el propio artícu.o 41.

Por su parte, la presunción posesoria, se basa en esta apariencia de titularidad, que lleva consigo un derecho a poseer - conservar la posesión en tanto no se haya dado la prescripción de los treinta años; no debiendo tener áplicación el artícưo 460, número 4, del Código civil, posesión de año y día.

Las pocas garantías que ofréce el Catálogo y su elevación a Registro público, puede ser un inconveniente para un buen sistema inmobiliario, puesto que ambas propiedades, pública y privada, han de convivir. Consideramos que el sistema de comprobación de ambas propiedades debe ser el mismo, y el buen camino está en la coordinación del Catastro con el Registro de la Propiedad. Sobre esta base queda garantizada la subsanación de los defectos de inmatriculación que permiten utilizar las garantías registrales a los defraudadores del dominio púbico, que tan acertadamente persigue la nueva Ley de Montes; y de este modo los principios hipotecarios de legitimación, fe pública registral y especialidad, cobrarán su plena efectividad, haciendo que la inscripción obligada por parte del Estado y Entidades públicas, sea algo sustantivo y no meramente preventivo.

Manuel Jesús NúNez Ruiz

Licenciado en Nerecho y en Ciencias Politicas

Secretario de i. ${ }^{2}$ categoria de Administración local 